\title{
Computational Study of the Electron Spectra of Acetamide and $\mathbf{N}$-methylformamide
}

\author{
Delano P. Chong
}

Department of Chemistry, 2036 Main Mall, University of British Columbia, Vancouver, B.C., Canada V6T 1 Z1

Author's e-mail address: chong@chem.ubc.ca

RECEIVED: January 7, 2017 * REVISED: May 21, 2017 * ACCEPTED: May 22, 2017

THIS PAPER IS DEDICATED TO PROFESSOR LEO KLASINC ON THE OCCASION OF HIS 80 ${ }^{\text {TH }}$ BIRTHDAY

Abstract: The molecular structures of the three conformers of acetamide are first studied by ab initio method of CCSD/cc-pVTZ. Using the optimized geometry of each species, we apply established and/or developing methods to compute several physical properties of acetamide and compare them with available experimental data. The properties include dipole moments, polarizabilities, ionization energies of both valence and core electrons, and absorption spectra of both valence and core electrons. Similar results for $\mathrm{N}$-methylformamide are included for comparison.

Keywords: acetamide, $\mathrm{N}$-methylformamide, structure, electron spectra.

\section{INTRODUCTION}

C OMPARISON of the performance of various levels of theory and different basis sets on molecular structure and energies has been reported in several papers. For example, Helgaker et al. ${ }^{[1]}$ compared the prediction of bond lengths of 28 small molecules by ab initio methods, from Hartree-Fock to coupled cluster singles and doubles $(\mathbf{C C S D})^{[2]}$ plus perturbative triples correction $(\mathrm{T})$, with large basis sets up to cc-pVQZ; while Bak et al. ${ }^{[3]}$ used similar methods with even larger basis set CCSD(T)/cc-pCVQZ on the equilibrium structures (bond lengths and bond angles) of 19 small molecules. For many molecules, the levels of theory such as $\operatorname{CCSD}(\mathrm{T}) / \mathrm{cc}-\mathrm{pVQZ}$ will be too demanding computationally. On the other hand, use of small basis sets instead may be inadequate. In the present study, the level of theory CCSD/cc-PVTZ is chosen for the determination of the molecular structure.

Acetamide is an interesting molecule for several reasons. First, it is one of the best models of the peptide bond; secondly, there is the question of whether or not the arrangement of the bonds around the nitrogen atom is planar or pyramidal, the question being common to other nitrogen-containing molecules such as amines, amides, and nitro molecules; ${ }^{[4]}$ thirdly, pyramidization aside, there is the question of the planarity of the heavy atom framework $\mathrm{C}(\mathrm{CO}) \mathrm{N} ;{ }^{[5]}$ furthermore, the rotation of the methyl group leads to three conformers; ${ }^{[4]}$ and finally the low methyl rotation barrier leads to an ambiguity of nonplanar equilibrium structures versus an effective planar ground state. ${ }^{[6]}$ Demaison et al. ${ }^{[6]}$ made an extensive study of the planarity of the CONH linkage in formamide, cyanamide, acetamide, urea, carbamic acid, methylamine, dimethyl ether, and methyl carbamate. They concluded that the CONH linkage is quite complex. Because of the exceedingly low barriers of the internal rotation of the methyl group, the ground state may be considered planar, in spite of the nonplanar equilibrium structure. Ilyushin et al. ${ }^{[7]}$ studied the complicated procedure of the labelling problem in the analysis of their Fourier transform microwave spectrum of acetamide. With the focus of this investigation on the electron spectra of acetamide, we make a simplifying assumption that the electron spectra of acetamide can be approximated by the average of those of the three conformers.

$\mathrm{N}$-methylformamide is an isomer of acetamide and similar results for methylformamide are included for comparison. 
In any case, we apply established methods to predict the ionization and excitation spectra of both valence and core electrons using the geometry optimized by CCSD/ccpVTZ method. The computational predictions agree very well with the rather limited experimental results of the ionization energies, available for outer valence electrons only, and suggest similar reliability of other computational results also. We therefore urge experimentalists to measure (a) ionization energies in the inner valence region. (b) core-electron binding energies, (c) valence shell electron energy loss spectra, and (d) X-ray absorption spectra, of both these interesting molecules acetamide and $\mathrm{N}$-methylformamide.

\section{COMPUTATION DETAILS}

In this study, we use two computer program packages: Gaussian09 ${ }^{[8]}$ and ADF13. ${ }^{[9]}$ No new methods are used in this work. As mentioned in the introduction, the method of geometry used is CCSD/cc-pVTZ, available in the Gaussian09 program. The Gaussian basis set cc-pVTZ is abbreviated as Basis $\mathrm{C}$ in this work. For dipole moments and static polarizabilities, we prefer the exchangecorrelation potential $V_{\mathrm{xc}}$ known as statistical averaging of orbital potentials (SAOP) ${ }^{[10-12]}$ available in the ADF package, in the belief that use of $V_{\mathrm{xc}}=\mathrm{SAOP}$ will lead to better description of the electron density. In the ADF package, there is an efficient basis set of even-tempered Slater-type orbital called et-pVQZ, ${ }^{[13]}$ which is abbreviated at Basis $Q$. Therefore, the dipole moment and static polarizabilities are calculated by the method of SAOP/Basis $\mathrm{Q} /$ /CCSD/Basis C.

For vertical ionization energies (VIEs) of valence electrons, also known as vertical ionization potentials (VIPs), we use the method $\triangle \mathrm{PBEO}(\mathrm{SAOP}) /$ et-pVQZ, which was developed in 2009[14] and has been applied to many molecules. The abbreviation means the total energy difference between the neutral parent molecule and the valence-hole cation calculated with the parameter-free Perdew-Burke-Ernzerhof (PBE0) exchange-correlation functional[ ${ }^{[15,16]}$ for the electron density obtained with $V_{\mathrm{xc}}=$ SAOP. For core-electron binding energies (CEBEs) of $C$ to $F$, we recommend the method developed much earlier in $1999,{ }^{[17]}$ namely $\Delta$ PW86x-PW91C $+C_{\text {rel, }}$ which stands for the total energy difference calculated with the combination of Perdew-Wang 1986 exchange functional[ ${ }^{[18]}$ and PerdewWang 1991 correlation functional. ${ }^{[19]}$ A small relativistic correction $C_{\text {rel }}$ derived empirically in $1995^{[20]}$ is added. The correction $C_{\text {rel }}$ is in the form of:

$$
C_{\mathrm{rel}}=K \cdot X_{\mathrm{nr}}^{N}
$$

where $K=0.2198 \times 10^{-6}$ and $N=2.178$ when the nonrelativistic value $X_{\mathrm{nr}}$ and the correction $C_{\text {rel }}$ are both in units of $\mathrm{eV}$. This method for CEBEs of organic and other small molecules have been tested on many systems. ${ }^{[21,22]}$

For excitation of valence electrons, the procedure of time-dependent density functional theory (TDDFT) using $V_{\mathrm{xc}}=\mathrm{SAOP}$ has been tested in many molecules. The TDDFT procedure produces excited singlet states with oscillator strengths as well as triplet states. The procedure for core electron excitations is more complicated. Blind application of TDDFT(SAOP) would be met with disaster because we would need to perform a configuration interaction (CI) calculation with a very large number of singly excited configurations. Stener et al. ${ }^{[23]}$ proposed a shortcut by allowing only excitations from the core orbitals for the TDDFT calculation. Such a "reduced window" approximation is somewhat analogous to the usual separation of rotations and vibrations. We have gained some experience with this shortcut. Although such a shortcut greatly reduces the size of the $\mathrm{Cl}$ calculation, such an approximation leads to two disadvantages: (a) The excitation energies are too low by tens of electron volts, and (b) the intensities are only qualitatively correct. To overcome (a), we can shift the entire X-ray absorption spectra (XAS) by a value determined from the difference between one of the TDDFT triplet energies and the one calculated by the method of $\Delta \mathrm{PW} 86-\mathrm{PW} 91+C_{\text {rel. }}$. The state for the evaluation of this shift is chosen to be the triplet state which corresponds to the singlet with the most intensity. Because of (b), we must realize that XAS spectra computed by convolution of the calculated energies and intensities would also be unreliable.

Finally, the energies of non-resonant X-ray emission spectra (XES) are simply the differences between VIEs of valence and core orbitals, while the energies of resonant XES are the differences between valence and core excitation energies. The intensities of XES are more complicated and are outside the scope of the present study.

\section{RESULTS AND DISCUSSION}

Following Samdal, ${ }^{[4]}$ we call the three conformers of acetamide by the names syn, anti, and perp. In Table 1 , we summarize the energies, rotational parameters, dipole moment, and static polarizabities of the three conformers. The three conformers have very similar energies (with perp being the lowest). It is therefore quite likely that the Boltzmann distribution is not far from $1 / 3$ for each conformer and so our simplifying assumption would not be far wrong. Our average $A$ and $C$ rotational parameters are close to those of Samdal's calculation, while the B parameter is close to the observed value. Corresponding results on $\mathrm{N}$-methylformamide included for comparison are very similar to those for acetamide. 
Table 1. Calculated energies (in hartrees), rotational parameters (in MHz), dipole moments (in debyes), and static polarizabilities (in au) of the three conformers of acetamide(g) and $\mathrm{N}$-methylformamide

\begin{tabular}{|c|c|c|c|c|c|c|c|c|}
\hline & \multicolumn{7}{|c|}{ Acetamide } & \multirow{2}{*}{$N$-methylformamide } \\
\hline & syn & anti & perp & Average & Observed & $M P 2^{(c)}$ & B3LYP(c) & \\
\hline$C C S D+208$ & -0.856707 & -0.856650 & -0.856846 & & & & & -0.839698 \\
\hline $\operatorname{ccs}(T)+208$ & -0.889818 & -0.889819 & -0.890009 & & & & & -0.873144 \\
\hline$A$ & 10840 & 10902 & 10842 & 10861 & $10173^{(\mathrm{a})}$ & 10860 & 10872 & 19545 \\
\hline B & 9379 & 9330 & 9359 & 9356 & $9342^{(a)}$ & 9457 & 9281 & 6343 \\
\hline $\mathrm{C}$ & 5191 & 5188 & 5191 & 5190 & $5144^{(a)}$ & 5218 & 5167 & 4935 \\
\hline$\mu$, debyes & 4.163 & 4.152 & 4.088 & 4.134 & $3.68 \pm 0.03^{(b)}$ & 4.20 & 3.82 & 4.268 \\
\hline$\alpha_{\text {ave, }}$ au & 38.39 & 38.54 & 38.57 & 38.50 & & & & 38.61 \\
\hline$\Delta \alpha, a u$ & 13.95 & 14.27 & 13.95 & 14.06 & & & & 17.95 \\
\hline
\end{tabular}

(a) Average experimental values of Kojima, ${ }^{[24]}$ Suenram, ${ }^{[25]}$ Yamaguchi, ${ }^{[26]}$ and layushin. ${ }^{[7]}$

(b) From Stark effect. [24]

(c) Samdal[ ${ }^{[4]}$ with cc-pVTZ basis.

Table 2. Bond lengths (in Angstroms) of acetamide and $\mathrm{N}$-methylformamide

\begin{tabular}{|c|c|c|c|c|c|c|c|c|c|c|c|}
\hline & Method & Ref. & conformer & $\mathrm{CC}$ & $\mathrm{CN}$ & $\mathrm{CO}$ & $\mathrm{NH}_{\mathrm{c}}$ & $\mathrm{NH}_{\mathrm{t}}$ & $\mathrm{CH}$ & $\mathrm{CH}$ & $\mathrm{CH}$ \\
\hline \multirow[t]{2}{*}{ Expt } & Electron & {$[27]$} & & 1.53 & 1.36 & 1.21 & $(1.02)$ & $(1.02)$ & (1.09) & (1.09) & (1.09) \\
\hline & diffraction & {$[28]$} & & 1.519 & 1.380 & 1.220 & 1.022 & 1.022 & 1.124 & 1.124 & 1.124 \\
\hline \multirow[t]{10}{*}{ Calc } & $\mathrm{MP} 2 / 6-31+\mathrm{G} * *$ & [5] & & 1.511 & 1.371 & 1.232 & 1.007 & 1.005 & 1.085 & 1.088 & 1.089 \\
\hline & Pulay force field & [29] & & 1.5182 & 1.3633 & 1.2187 & 0.9918 & 0.9943 & 1.0830 & 1.0771 & 1.0771 \\
\hline & $\mathrm{MP} 2 / 6-31+\mathrm{G} * *$ & [30] & syn & 1.5137 & 1.3693 & 1.2334 & 1.0070 & 1.0046 & 1.0901 & 1.0851 & 1.0851 \\
\hline & MP2/cc-pVTZ & [4] & perp & 1.5040 & 1.3597 & 1.2163 & 1.0021 & 0.9991 & 1.0812 & 1.0840 & 1.0856 \\
\hline & & & anti & 1.5046 & 1.3579 & 1.2164 & 1.0022 & 0.9984 & 1.0835 & 1.0835 & 1.0835 \\
\hline & MP2/pVQZ+corr & {$[6]$} & perp & 1.509 & 1.362 & 1.216 & 1.003 & 1.000 & 1.082 & 1.085 & 1.086 \\
\hline & CCSD/cc-pVTZ & This & syn & 1.5139 & 1.3640 & 1.2126 & 1.0018 & 0.9995 & 1.0832 & 1.0902 & 1.0902 \\
\hline & & work & anti & 1.5141 & 1.3619 & 1.2131 & 1.0022 & 0.9989 & 1.0884 & 1.0881 & 1.0881 \\
\hline & & & perp & 1.5133 & 1.3688 & 1.2118 & 1.0033 & 1.0011 & 1.0853 & 1.0892 & 1.0908 \\
\hline & & & average & 1.5138 & 1.3649 & 1.2125 & 1.0025 & 0.9998 & 1.0856 & 1.0892 & 1.0897 \\
\hline \multirow[t]{2}{*}{$\mathrm{NMF}^{(\mathrm{a})}$} & CCSD/cc-pVTZ & This & & & 1.4502 & 1.2118 & & 1.0008 & 1.0870 & 1.0890 & 1.0998 \\
\hline & & work & & & 1.3522 & & & & & & \\
\hline
\end{tabular}

(a) $\mathrm{N}$-methylformamide.

The bond lengths from our CCSD/cc-pVTZ computations are compared with previous calculations and experimental values in Table 2. It can be seen that our CCSD/cc-pVTZ procedure underestimates all bond lengths of acetamide.

The results of our computation of vertical ionization energies are compared with experiment in Tables 3 and 4.

Table 3. Vertical ionization energies (in eV) of acetamide

\begin{tabular}{|c|c|c|c|c|c|c|c|c|c|c|}
\hline \multicolumn{5}{|c|}{ Experiment } & \multicolumn{6}{|c|}{ This work } \\
\hline $\begin{array}{l}\text { Meeks } \\
1975^{[31]}\end{array}$ & $\begin{array}{c}\text { McGlynn } \\
1975^{[32]}\end{array}$ & $\begin{array}{c}\text { Asbrink } \\
1981^{[33]} \\
\end{array}$ & $\begin{array}{c}\text { Kishimoto } \\
2001^{[34]}\end{array}$ & $\begin{array}{c}\text { best } \\
\text { estimate }\end{array}$ & $\mathrm{MO}$ & syn & anti & perp $^{(a)}$ & average & ave - best \\
\hline 9.95 & 9.95 & 10.0 & 9.86 & 9.92 & $13 a^{\prime}$ & 9.85 & 9.85 & 9.91 & 9.87 & -0.05 \\
\hline 10.34 & 10.34 & 10.4 & 10.32 & 10.33 & $3 a^{\prime \prime}$ & 10.38 & 10.37 & 10.47 & 10.41 & 0.08 \\
\hline \multirow[t]{2}{*}{12.98} & 12.98 & 13.0 & 13.01 & 12.99 & $2 a^{\prime \prime}$ & 12.94 & 12.90 & 12.94 & 12.93 & -0.06 \\
\hline & & 14.1 & 14.08 & 14.08 & $12 a^{\prime}$ & 13.82 & 13.32 & 14.06 & 13.73 & -0.35 \\
\hline 14.12 & 14.12 & $\approx 14.5$ & 14.43 & 14.22 & $11 a^{\prime}$ & 14.05 & 14.04 & 14.08 & 14.06 & -0.16 \\
\hline 15.4 & 15.42 & 15.4 & 15.39 & 15.41 & $1 a^{\prime \prime}$ & 15.20 & 15.14 & 15.21 & 15.18 & -0.23 \\
\hline 16.0 & 16.02 & 16.0 & 16.13 & 16.08 & $10 a^{\prime}$ & 15.65 & 15.69 & 15.69 & 15.68 & -0.40 \\
\hline 18.0 & 17.96 & 18.0 & 18.09 & 18.03 & $9 a^{\prime}$ & 18.11 & 18.15 & 18.04 & 18.10 & 0.07 \\
\hline \multirow[t]{9}{*}{19.3} & 19.46 & 19.4 & 19.34 & 19.40 & $8 a^{\prime}$ & 19.26 & 19.30 & 19.18 & 19.25 & -0.15 \\
\hline & & 23.9 & & & $7 a^{\prime}$ & 23.60 & 23.59 & 23.61 & 23.60 & \\
\hline & & & & & $6 a^{\prime}$ & 28.34 & 28.36 & 28.36 & 28.35 & \\
\hline & & & & & $5 a^{\prime}$ & 31.95 & 31.92 & 32.00 & 31.96 & \\
\hline & & & & & $4 a^{\prime}\left(C^{*} H_{3}\right)$ & 291.21 & 291.22 & 291.23 & 291.21 & \\
\hline & & & & & $3 a^{\prime}\left(C^{*}=0\right)$ & 293.88 & 293.87 & 293.90 & 293.88 & \\
\hline & & & & & $2 a^{\prime}(N 1 s)$ & 406.21 & 406.25 & 406.23 & 406.23 & \\
\hline & & & & & $1 a^{\prime}(01 s)$ & 537.20 & 537.14 & 537.25 & 537.20 & \\
\hline & & & & & & & \multicolumn{3}{|c|}{ Mean absolute deviation } & 0.17 \\
\hline
\end{tabular}

\footnotetext{
(a) For MOs 16a to $5 \mathrm{a}$.
} 
Table 4. Vertical ionization energies (in eV) of $\mathrm{N}$-methylformamide

\begin{tabular}{|c|c|c|c|c|c|c|}
\hline \multicolumn{4}{|c|}{ Experiment } & \multicolumn{3}{|c|}{ This work } \\
\hline Brundle $1969^{[35]}$ & Keller $1986^{[36]}$ & Li $2016^{[37]}$ & best estimate & MO & DFT & DFT - best \\
\hline $9.87 \pi$ & $10.1 \pi$ & $\approx 9.86$ & 9.87 & $3 a^{\prime \prime}$ & 9.96 & 0.09 \\
\hline 10.05 & 10.1 & $\approx 10.06$ & 10.05 & 13a' & 10.03 & -0.02 \\
\hline \multirow{2}{*}{13.2} & $13.3 \pi$ & $\approx 13.71$ & $13.2_{5}$ & $2 a^{\prime \prime}$ & 13.18 & $-0.0_{7}$ \\
\hline & 14.1 & $\approx 14.16$ & 14.1 & $12 a^{\prime}$ & 13.76 & $-0.3_{4}$ \\
\hline 14.3 & 14.5 & & 14.4 & $11 a^{\prime}$ & 14.30 & -0.1 \\
\hline 15.7 & 15.6 & & $15.6_{5}$ & $10 a^{\prime}$ & 15.34 & $-0.3_{1}$ \\
\hline 15.7 & $15.6 \pi$ & & 15.65 & $1 a^{\prime \prime}$ & 15.41 & $-0.2_{4}$ \\
\hline 18.3 & 18.13 & & 18.13 & $9 a^{\prime}$ & 18.03 & -0.10 \\
\hline \multirow[t]{9}{*}{$\approx 20$} & & & & $8 a^{\prime}$ & 1943 & \\
\hline & & & & $7 a^{\prime}$ & 22.88 & \\
\hline & & & & $6 a^{\prime}$ & 28.75 & \\
\hline & & & & $5 a^{\prime}$ & 31.94 & \\
\hline & & & & $4 a^{\prime}\left(C^{*} \mathrm{H}_{3}\right)$ & 291.22 & \\
\hline & & & & $3 a^{\prime}\left(C^{*}=0\right)$ & 293.59 & \\
\hline & & & & 2a' (N1s) & 406.33 & \\
\hline & & & & $1 a^{\prime}(01 s)$ & 537.29 & \\
\hline & & & & \multicolumn{2}{|c|}{ Mean absolute deviation } & $0.1_{6}$ \\
\hline
\end{tabular}

The mean absolute deviation (MAD) is $0.17 \mathrm{eV}$ for acetamide (that for the perp conformer is marginally smaller at $0.13 \mathrm{eV}$ ) and $0.1_{6} \mathrm{eV}$ for $\mathrm{N}$-methylformamide. We could not find experimental values for the inner valence or core region. It would be interesting to find out how reliable our DFT procedures are for those vertical ionization energies.

Acetamide and $\mathrm{N}$-methylformamide involve methyl substitution of different hydrogen atoms of formamide. All three molecules have the $\mathrm{O}=\mathrm{C}-\mathrm{N}$ linkage. The calculated CEBEs of the carbonyl carbon are: $294.19,{ }^{[38]} 293.88$, and $293.59 \mathrm{eV}$ for formamide, acetamide, and $\mathrm{N}$ methylformamide, respectively. The values indicate the electron-donating effect of methyl leading to a lowering of the CEBE of carbonyl carbon by $0.3 \mathrm{eV}$. Similarly, the CEBEs of N1s are $406.55,{ }^{[38]} 406.23$, and $406.33 \mathrm{eV}$ for formamide, acetamide, and $\mathrm{N}$-methylformamide, respectively, providing a lowering of $0.2 \mathrm{eV}$ for the electron donating effect of methyl substitution on the CEBE of N. The effects are quite small compared to the much larger increase of the CEBEs of $O$, which are $517.78,{ }^{[38]} 537.20$ and $537.29 \mathrm{eV}$, respectively, due to effects other than simple potential from inductive charges.

The excitations of valence electrons are presented in Tables 5 and 6 . Excitations of valence electrons to lower excited states have very low oscillator strengths. The observable excitations occur in the vacuum ultraviolet region. In any case, the TDDFT(SAOP) procedure gives very

Table 5. Excited states (singlet absorption maxima in $\mathrm{nm}$ and triplet energies in $\mathrm{eV}$ ) of the conformers of acetamide calculated by TDDFT(SAOP)/Basis Q//CCSD/Basis C

\begin{tabular}{|c|c|c|c|c|c|c|c|c|}
\hline & Excited state & syn & anti & perp $^{(a)}$ & Average (sum) & $\mathrm{Obs}^{(\mathrm{b})}$ & CASPT2 $^{\text {(c) }}$ & $\mathrm{MRCl}^{(\mathrm{d})}$ \\
\hline \multirow[t]{11}{*}{ Singlets } & $1 A^{\prime \prime}$ & $212(0.001)$ & $211(0.000)$ & $214(0.001)$ & $212(0.002)$ & & $1 A^{\prime \prime} 224(0.002)$ & $1 A^{\prime \prime} 209$ \\
\hline & $2 A^{\prime}$ & $201(0.026)$ & $202(0.026)$ & $200(0.026)$ & $201(0.078)$ & & $2 A^{\prime \prime} 194(0.022)$ & $2 A^{\prime \prime} 206$ \\
\hline & $2 A^{\prime \prime}$ & $181(0.009)$ & $181(0.010)$ & $178(0.012)$ & $180(0.031)$ & & $2 A^{\prime} 194(0.018)$ & $2 A^{\prime} 197$ \\
\hline & $3 A^{\prime}$ & $173(0.021)$ & $172(0.012)$ & $173(0.019)$ & $173(0.052)$ & & $3 A^{\prime \prime} 177(0.001)$ & $3 A^{\prime} 177$ \\
\hline & $4 A^{\prime}$ & $164(0.146)$ & $165(0.024)$ & $163(0.114)$ & $164(0.284)$ & 166 & $3 A^{\prime} 174(0.060)$ & $3 A^{\prime \prime} 174$ \\
\hline & $5 A^{\prime}$ & $161(0.047)$ & $161(0.181)$ & $161(0.076)$ & $161(0.304)$ & & $4 A^{\prime} 172(0.292)$ & $4 A^{\prime} 171$ \\
\hline & $3 A^{\prime \prime}$ & $158(0.006)$ & $157(0.005)$ & $156(0.008)$ & 157 (0.019) & 158 & $5 A^{\prime} 169(0.013)$ & $5 A^{\prime} 170$ \\
\hline & $4 A^{\prime \prime}$ & $154(0.003)$ & $152(0.000)$ & $153(0.012)$ & $153(0.015)$ & 155 & $6 A^{\prime} 168(0.009)$ & $4 A^{\prime \prime} 169$ \\
\hline & $6 A^{\prime}$ & $151(0.004)$ & $151(0.047)$ & $150(0.009)$ & $151(0.060)$ & & $4 A^{\prime \prime} 165(0.000)$ & $5 A^{\prime \prime} 168$ \\
\hline & $5 A^{\prime \prime}$ & $149(0.000)$ & $151(0.011)$ & $148(0.025)$ & $149(0.036)$ & & $5 A^{\prime \prime} 160(0.004)$ & $6 A^{\prime} 151$ \\
\hline & $7 A^{\prime}$ & $148(0.035)$ & 144 (0.039) & $148(0.009)$ & $147(0.083)$ & & $7 A^{\prime} 155(0.000)$ & \\
\hline \multirow[t]{4}{*}{ Triplets } & $1 \mathrm{~A}^{\prime \prime}$ & 5.42 & 5.49 & 5.38 & 5.43 & & 5.24 & \\
\hline & $1 A^{\prime}$ & 5.84 & 5.88 & 5.85 & 5,86 & & 5.57 & \\
\hline & $2 A^{\prime}$ & 6.11 & 6.08 & 6.12 & 6.10 & & 6.37 & \\
\hline & $2 A^{\prime \prime}$ & 6.69 & 6.68 & 6.78 & 6.72 & & 6.21 & \\
\hline
\end{tabular}

\footnotetext{
(a) The states are $2 \mathrm{~A}$ to $12 \mathrm{~A}$ for singlets and $1 \mathrm{~A}$ to $4 \mathrm{~A}$ for triplets.

(b) Kaya 1967. [39]

(c) Serrano-Andres $1996^{[40]}$ for the syn conformer.

(d) Hirst $1997^{[30]}$ for the syn conformer.
} 
Table 6. Excited states (singlet absorption maxima in $\mathrm{nm}$ and triplet energies in $\mathrm{eV}$ ) of $\mathrm{N}$-methylformamide calculated by TDDFT(SAOP)/Basis Q//CCSD/Basis C

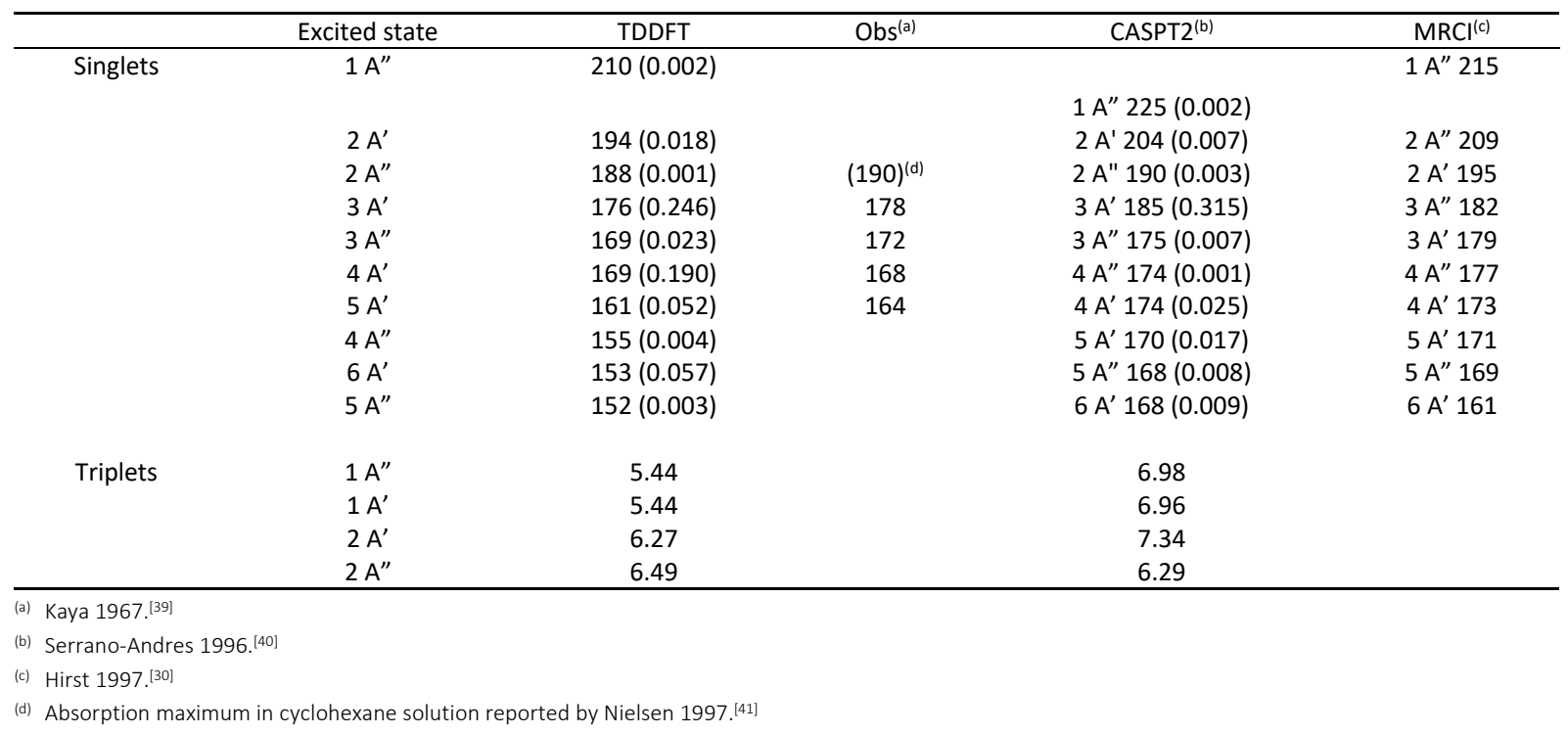

nice prediction of the UV absorption spectrum, as shown in Tables 5 and 6 . The low excitations to triplet states are included in Tables 5 and 6, for the benefit of workers measuring valence shell electron loss spectra.

Finally, the prediction of X-ray absorption spectra, as shown in the last two columns in Tables 7 and 8 , is more complicated. The shift must be added to the TDDFT results obtained by the reduced window approximation. For example, the triplet excitation energy of $01 \mathrm{~s}$ to $4 a$ " for the syn conformer of acetamide is $508.33 \mathrm{eV}$ by TDDFT with reduces energy window and $531.67 \mathrm{eV}$ by $\triangle \mathrm{PW} 86-\mathrm{PW} 91$ (both before approximate relativistic correction $C_{\text {rel }}$ is

Table 7. X-ray absorption spectra of acetamide calculated by TDDFT(SAOP) with reduced energy window and shifts needed based on $\triangle$ (PW86PW91). Absorption energies are given in $\mathrm{eV}$ and $f$-values, in parentheses

\begin{tabular}{|c|c|c|c|c|c|c|c|c|}
\hline & & & syn & anti & perp & Average (sum) ${ }^{(\mathrm{a})}$ & Shifted & Rel. intensity \\
\hline \multirow[t]{8}{*}{ CK } & $A^{\prime \prime}$ & $4 a^{\prime}$ to $4 a^{\prime \prime}$ & $268.77(0.0002)$ & $268.83(0.0001)$ & $268.72(0.0001)$ & $268.77(0.0004)$ & 284.88 & 0.004 \\
\hline & $A^{\prime}$ & $4 a^{\prime}$ to $14 a^{\prime}$ & $269.39(0.0006)$ & 269.39 (0.0009) & $269.40(0.0006)$ & $269.39(0.0020)$ & 285.50 & 0.022 \\
\hline & $A^{\prime}$ & $4 a^{\prime}$ to $15 a^{\prime}$ & $270.45(0.0031)$ & $270.51(0.0033)$ & $270.49(0.0031)$ & $270.48(0.0095)$ & 286.59 & 0.102 \\
\hline & $A^{\prime}$ & $4 a^{\prime}$ to $16 a^{\prime}$ & $270.85(0.0013)$ & $270.73(0.0047)$ & $270.85(0.0020)$ & $270.81(0.0080)$ & 286.92 & 0.086 \\
\hline & $A^{\prime}$ & $4 a^{\prime}$ to $17 a^{\prime}$ & $271.36(0.0006)$ & $271.38(0.0023)$ & $271.28(0.0075)$ & $271.34(0.0104)$ & 287.49 & 0.112 \\
\hline & $A^{\prime \prime}$ & $4 a^{\prime}$ to $5 a^{\prime \prime}$ & $271.28(0.0080)$ & $271.43(0.0054)$ & $271.41(0.0002)$ & $271.37(0.0136)$ & 287.53 & 0.146 \\
\hline & $A^{\prime \prime}$ & $3 a^{\prime}$ to $4 a^{\prime \prime}$ & 271.61 (0.0439) & $271.66(0.0451)$ & 271.55 (0.0039) & 271.61 (0.0929) & 287.63 & (1) \\
\hline & & shift & 16.13 & 16.25 & 15.81 & 16.06 & & \\
\hline \multirow[t]{7}{*}{ NK } & $A^{\prime \prime}$ & $2 a^{\prime}$ to $4 a^{\prime \prime}$ & $380.60(0.0073)$ & $380.74(0.0093)$ & 380.57 (0.0072) & $380.64(0.0238)$ & 401.95 & 0.98 \\
\hline & $A^{\prime}$ & $2 a^{\prime}$ to $14 a^{\prime}$ & $381.22(0.0017)$ & $381.22(0.0020)$ & $381.24(0.0020)$ & $381.23(0.0057)$ & 402.54 & 0.23 \\
\hline & $A^{\prime}$ & $2 a^{\prime}$ to $15 a^{\prime}$ & $382.19(0.0033)$ & $382.29(0.0033)$ & $382.23(0.0034)$ & $382.24(0.0100)$ & 403.55 & 0.41 \\
\hline & $A^{\prime}$ & $2 a^{\prime}$ to $16 a^{\prime}$ & $382.67(0.0089)$ & $382.55(0.0070)$ & $382.67(0.0085)$ & $382.63(0.0244)$ & 403.94 & (1) \\
\hline & $A^{\prime \prime}$ & $2 a^{\prime}$ to $5 a^{\prime \prime}$ & $382.99(0.0036)$ & $383.19(0.0025)$ & $383.00(0.0033)$ & $383.06(0.0104)$ & 404.37 & 0.43 \\
\hline & $A^{\prime}$ & $2 a^{\prime}$ to $17 a^{\prime}$ & $383.10(0.0001)$ & $383.18(0.0021)$ & $383.29(0.0021)$ & $383.19(0.0043)$ & 404.50 & 0.18 \\
\hline & & shift & 21.54 & 21.42 & 20.67 & 21.21 & & \\
\hline \multirow[t]{7}{*}{ OK } & $A^{\prime \prime}$ & $1 a^{\prime}$ to $4 a^{\prime \prime}$ & $508.80(0.0206)$ & $508.76(0.0184)$ & $508.76(0.0194)$ & $508.77(0.0584)$ & 532.32 & (1) \\
\hline & $A^{\prime}$ & $1 a^{\prime}$ to $14 a^{\prime}$ & $509.05(0.0003)$ & $508.97(0.0003)$ & $509.09(0.0012)$ & $509.04(0.0018)$ & 532.59 & 0.031 \\
\hline & $A^{\prime}$ & $1 a^{\prime}$ to $15 a^{\prime}$ & $510.08(0.0014)$ & $510.07(0.0012)$ & $510.13(0.0013)$ & 510.09 (0.0039) & 533.64 & 0.067 \\
\hline & $A^{\prime}$ & $1 a^{\prime}$ to $16 a^{\prime}$ & $510.56(0.0004)$ & $510.33(0.0006)$ & $510.57(0.0006)$ & $510.49(0.0016)$ & 534.04 & 0.027 \\
\hline & $A^{\prime}$ & $1 a^{\prime}$ to $17 a^{\prime}$ & $511.12(0.0001)$ & $511.04(0.0002)$ & $510.98(0.0014)$ & $511.05(0.0017)$ & 534.60 & 0.029 \\
\hline & $A^{\prime \prime}$ & $1 a^{\prime}$ to $5 a^{\prime \prime}$ & $510.96(0.0027)$ & $511.06(0.0017)$ & $511.21(0.0001)$ & $511.08(0.0045)$ & 534.63 & 0.077 \\
\hline & & shift & 23.33 & 23.41 & 23.34 & 23.36 & & \\
\hline
\end{tabular}

(a) Average of XAS energies (sum of $f$-values), including approximate relativistic corrections of $0.05,0.10$, and $0.19 \mathrm{eV}$ for excitations form C1s, N1s, and O1s, respectively. 
Table 8. X-ray absorption spectra of $\mathrm{N}$-methylformamide calculated by TDDFT(SAOP) with reduced energy window and shifts needed based on $\triangle$ (PW86PW91). Absorption energies are given in $\mathrm{eV}$ and $f$-values, in parentheses

\begin{tabular}{|c|c|c|c|c|}
\hline & & & $\Delta E$ (f-value) & Shifted $^{(\mathrm{a})}($ rel int $)$ \\
\hline \multirow[t]{9}{*}{ CK } & $1 \mathrm{~A}^{\prime \prime}$ & $4 a^{\prime}$ to $4 a^{\prime \prime}$ & $269.47(0.000)$ & $287.39(0.001)$ \\
\hline & $2 A^{\prime}$ & $4 a^{\prime}$ to $14 a^{\prime}$ & $270.21(0.002)$ & $288.13(0.059)$ \\
\hline & $3 A^{\prime}$ & $4 a^{\prime}$ to $15 a^{\prime}$ & $271.09(0.001)$ & $289.01(0.021)$ \\
\hline & $2 A^{\prime \prime}$ & $3 a^{\prime}$ to $4 a^{\prime \prime}$ & $271.27(0.039)$ & 289.19 (1) \\
\hline & $4 \mathrm{~A}^{\prime}$ & $4 a^{\prime}$ to $16 a^{\prime}$ & $271.59(0.002)$ & $289.51(0.060)$ \\
\hline & $5 A^{\prime}$ & $3 a^{\prime}$ to $14 a^{\prime}$ & $271.62(0.001)$ & $289.54(0.038)$ \\
\hline & $5 A^{\prime}$ & $4 a^{\prime}$ to $17 a^{\prime}$ & $271.88(0.006)$ & $289.80(0.162)$ \\
\hline & $3 A^{\prime \prime}$ & $4 a^{\prime}$ to $5 a^{\prime \prime}$ & $271.98(0.004)$ & $289.90(0.106)$ \\
\hline & & shift & 17.87 & \\
\hline \multirow[t]{7}{*}{ NK } & $A^{\prime \prime}$ & $2 a^{\prime}$ to $4 a^{\prime \prime}$ & $380.90(0.012)$ & 402.13 (1) \\
\hline & $A^{\prime}$ & $2 a^{\prime}$ to $14 a^{\prime}$ & $381.59(0.005)$ & $402.82(0.383)$ \\
\hline & $A^{\prime}$ & $2 a^{\prime}$ to $15 a^{\prime}$ & $382.20(0.002)$ & $403.43(0.179)$ \\
\hline & $A^{\prime}$ & $2 a^{\prime}$ to $16 a^{\prime}$ & $382.92(0.000)$ & $404.15(0.017)$ \\
\hline & $A^{\prime}$ & $2 a^{\prime}$ to $17 a^{\prime}$ & $383.20(0.001)$ & $404.43(0.059)$ \\
\hline & $A^{\prime \prime}$ & $2 a^{\prime}$ to $5 a^{\prime \prime}$ & $383.23(0.000)$ & $404.46(0.037)$ \\
\hline & & shift & 21.13 & \\
\hline \multirow[t]{7}{*}{ OK } & $A^{\prime \prime}$ & $1 a^{\prime}$ to $4 a^{\prime \prime}$ & $508.87(0.022)$ & $538.36 \quad(1)$ \\
\hline & $A^{\prime}$ & $1 a^{\prime}$ to $14 a^{\prime}$ & $509.27(0.001)$ & $538.76(0.006)$ \\
\hline & $A^{\prime}$ & $1 a^{\prime}$ to $15 a^{\prime}$ & $509.96(0.000)$ & $539.45(0.001)$ \\
\hline & $A^{\prime}$ & $1 a^{\prime}$ to $16 a^{\prime}$ & $510.64(0.000)$ & $540.13(0.017)$ \\
\hline & $A^{\prime \prime}$ & $1 a^{\prime}$ to $5 a^{\prime \prime}$ & $511.03(0.000)$ & $540.52(0.000)$ \\
\hline & $A^{\prime \prime}$ & $1 a^{\prime}$ to $6 a^{\prime \prime}$ & $511.81(0.000)$ & $540.52(0.012)$ \\
\hline & & shift & 29.29 & \\
\hline
\end{tabular}

added), leading to a shift of $23.33 \mathrm{eV}$. The predicted XAS for O1s and N1s shows a typical pattern, with a relatively intense excitation to the lowest unoccupied orbital, followed by less intense peaks. In contrast, the predicted XAS for C1s excitations is unexpected, with the most intense excitation given by $\mathrm{C} 1 \mathrm{~s}$ of the carbonyl carbon to $4 \mathrm{a}$ ".

\section{SUMMARY}

In the study, we propose a simplifying assumption that the properties of acetamide can be approximated by the average of the three conformers. The focus of this work is on the electron spectra of acetamide, including the ionization and excitation spectra of both the valence and core electrons. Results for $\mathrm{N}$-methylformamide are included for comparison. It is amazing how much alike the spectra of the two isomers are. The computational predictions agree well with the rather limited experimental results of the ionization energies, available for outer valence electrons only. We urge experimentalists to measure the other types of electron spectra, including the energies of excited triplet states by electron energy loss spectroscopy, of both interesting molecules acetamide and $\mathrm{N}$-methylformamide.
Acknowledgment. The author is grateful for the support of Scientific Computing \& Modeling, and to the reviewers for valuable suggestions. He also appreciates the vast contributions of Professor Leo Klasinc in the field of photoelectron spectroscopy and is grateful for the opportunity to celebrate his $80^{\text {th }}$ birthday with this paper.

\section{REFERENCES}

[1] T. Helgaker, J. Gauss, P. Jorgensen, J. Olsen, J. Chem. Phys. 1997, 106, 6430.

[2] For a discussion of CCSD and related methods, see G. E. Scuseria, H. F. Schaefer, J. Chem. Phys. 1989, 90, 3700.

[3] K. L. Bak, J. Gauss, P. Jorgensen, J. Olsen, T. Helgaker, J. F. Stanton, J. Chem. Phys. 2001, 114, 6548.

[4] S. Samdal, J. Mol. Struct. 1998, 440, 165.

[5] M. W. Wong, K. B. Wiberg, J. Phys. Chem. 1992, 96, 668.

[6] J. Demaison, A. G. Czaszar, I. Kleiner, H. Mollendal, J. Phys. Chem. A 2007, 111, 2574.

[7] V. V. layushin, F. A. Alekseev, S. F. Dyubko, I. Kleiner, J. T. Hougen, J. Mol. Spetrosc. 227 (2004) 115-139.

[8] M. J. Frisch, G. W. Trucks, H. B. Schlegel, G. E. Scuseria, M. A. Robb, J. R. Cheeseman, G. Scalmani, V. Barone, B. Mennucci, G. A. Petersson, H. Nakatsuji, M. Caricato, X. Li, H. P. Hratchian, A. F. Izmaylov, J. Bloino, G. Zheng, J. L. Sonnenberg, M. Hada, M. Ehara, K. Toyota, R. Fukuda, J. Hasegawa, M. Ishida, T. Nakajima, Y. Honda, O. Kitao, H, Nakai, T. Vreven, J. A. Montgomery, Jr., J. E. Peralta, F. Ogliaro, M. Bearpark, J. J. Heyd, E. Brothers, K. N. Kudin, V. N. Staroverov, R. Kobayashi, J. Normand, K. Raghavachari, A. Rendell, J. C. Burant, S. S. Iyengar, J. Tomasi, M. Cossi, N. Rega, J. Millam, M. Klene, J. E. Knox, J. B. Cross, V. Bakken, C. Adamo, J. Jaramillo, R. Gomperts, R. E. Stratmann, O. Yazyev, A. J. Austin, R. Cammi, C. Pomelli, J. W. Ochterski, R. L. Martin, K. Morokuma, V. G. Zakrzewski, G. A. Voth, P. Salvador, J. J. Dannenberg, S. Dapprich, A. D. Daniels, O. Farkas, J. B. Foresman, J. V. Ortiz, J. Cioslowski, D. J. Fox, Gaussian 09, Revision A.02, Gaussian, Inc., Wallingford CT, 2009.

[9] ADF program System, release 2013, Scientific Computing \& Modeling, NV, Amsterdam, 2013. For a comprehensive description of ADF, see G. te Velde, F. M. Bickelhaupt, E. J. Baerends, C. Fonseca Guerra, S. J. A, van Gisbergen, J. G. Snijders, T. Ziegler, J. Comput. Chem. 2001, 22, 931.

[10] O. V. Gritsenko, P. R. T. Schipper, E. J. Baerends, Chem. Phys. Lett. 1999, 302, 199.

[11] O. V. Gritsenko, P. R. T. Schipper, E. J. Baerends, Int. J. Quantum Chem. 2000, 76, 407. 
[12] P. R. T. Schipper, O. V. Gritsenko, S. van Gisbergen, E. J. Baerends, J. Chem. Phys. 2000, 112, 1344.

[13] D. P. Chong, E. van Lenthe, S. van Gisbergen, E. J. Baerends, J. Comput. Chem. 2004, 25, 1030.

[14] M. Segala, D. P. Chong, J. Electron Spectrosc. Rel. Phenom. 2009, 171, 18.

[15] J. P. Perdew, K. Burke, M. Ernzerhof, Phys. Rev. Lett. 1996, 77, 3865; Errata: Phys. Rev. Lett. 1997, 78, 1396.

[16] C. Adamo, V. Barone, J. Chem. Phys. 1999, 110, 6158.

[17] G. Cavigliasso, D. P. Chong, J. Chem. Phys. 1999, 111, 9485.

[18] J. P. Perdew, Y. Wang, Phys. Rev. B 1986, 33, 8800.

[19] J. P. Perdew, Y. Wang, Phys. Rev. B 1992, 45, 13244.

[20] D. P. Chong, J. Chem. Phys. 1995, 103, 1842.

[21] D. P. Chong, P. Aplincourt, C. Bureau, J. Phys. Chem. 2002, 106, 356.

[22] Y. Takahata, D. P. Chong, J. Electron Spectrosc. Rel. Phenom. 2003, 133, 69.

[23] M. Stener, G. Fronzoni, M. de Simone, Chem. Phys. Lett. 2003, 373, 115.

[24] T. Kojima, E. Yano, K. Nakagawa, S. Tsunekawa, J. Mol. Spectrosc. 1987, 122, 408.

[25] R. D. Suenram, G. Y. Golubiamikov, I. I. Leonov, J. T. Hougen, J. Ortigoso, I. Kleiner, G. T. Fraser, J. Mol. Spectrosc. 2001, 208, 188.

[26] A. Yamaguchi, S. Hagiwara, H. Odashima, K. Takagi, S. Tsunekawa, J. Mol. Spectrosc. 215 (2002) 144.

[27] M. Kimura, M. Aoki, Bull. Chem. Soc. Japan 1953, 26, 429.
[28] M. Kitano, K. Kuchitsu, Bull. Chem. Soc. Japan 1973, 46, 3048.

[29] V. J. Klimkowski, H. L. Sellers, I. Schafer, J. Mol. Struct. 1979, 54, 299.

[30] J. D. Hirst, D. M. Hirst, C. I. Brooks III, J. Phys. Chem. A 1997, 101, 4821.

[31] J. L. Meeks, J. F. Arnett, D. Lrson, S. P. McGlynn, Chem. Phys. Lett. 1975, 30, 190.

[32] S. P. McGlynn, J. L. Meeks, J. Electron Spectrosc. Rel. Phenom. 1975, 6, 269.

[33] L. Asbrink, A. Svensson, W. von Niessen, G. Bieri, J. Electron Spectrosc. Rel. Phenom. 1981, 24, 293.

[34] N. Kishimoto, Y. Osaka, K. Ohno, J. Electron Spectrosc. Rel. Phenom. 2001, 114-116, 183.

[35] C. R. Brundle, D. W. Turner, M. B. Robin, H. Basch, Chem. Phys. Lett. 1969, 3, 292.

[36] W. Keller, H. Morgner, W. A. Muller, Mol. Phys. 1986, $57,637$.

[37] Z. Li, M. M. Dawley, I. Carmichael, S. Ptasinska, Int. J. Mass Spectrom. 2016, 410, 36.

[38] D. P. Chong, J. Electron Spectrosc. Rel. Phenom. 2011, 184, 164.

[39] K. Kaya, S. Nagakura, Theoret. Chim. Acta 1967, 7, 117.

[40] L. Serrano-Andres, M. P. Fulscher, J. Am. Chem. Soc. 1996, 118, 12190.

[41] F. B. Nielsen, J. A. Schellman, J. Phys. Chem. 1967, 71, 2297. 